\title{
Dielectric behavior of mixed cadmium magnesium hydrogen phosphate crystal
}

\author{
K. K. Bamzai", Rashmi Gupta, Shivani Suri, Vishal Singh \\ Crystal Growth \& Materials Research Laboratory, Department of Physics and Electronics, University of Jammu, Jammu \\ 180006, India
}

*Corresponding author. Tel.: (+91) 191 2450939; E-mail: kkbamz@yahoo.com

Received: 06 January 2013, Revised: 16 April 2013 and Accepted: 01 May 2013

\section{ABSTRACT}

Magnesium hydrogen phosphate (MHP) and transition metal doped cadmium magnesium hydrogen phosphate (CdMHP) was synthesized in the form of crystalline material by room temperature solution technique known as gel encapsulation technique. The synthesized crystals were then characterized for their structural, mechanical and electrical investigations using various chemical and physical methods. X - ray diffraction analysis (XRD) establishes magnesium hydrogen phosphate and cadmium magnesium hydrogen phosphate belonging to orthorhombic crystal system with space group Pbca. The mechanical behaviour of these crystals was studied by calculating Vicker's hardness number. The behaviour of microhardness with applied load was observed to be complex. The electrical behaviour was carried out by calculating dielectric constant at different temperatures and for different frequencies. The dielectric constant $\left(\varepsilon^{\prime}\right)$ was found to be strongly dependent on temperature and frequency. The transition metal doping of cadmium in magnesium hydrogen phosphate remarkably decrease the value of dielectric constant from 68 to 23 . The transition temperature also decreases from $330^{\circ} \mathrm{C}$ in case of magnesium hydrogen phosphate to $310^{\circ} \mathrm{C}$ in case of cadmium magnesium hydrogen phosphate. Copyright (C) 2014 VBRI press.

Keywords: Crystal growth; X-ray diffraction; microhardness; dielectric constant.

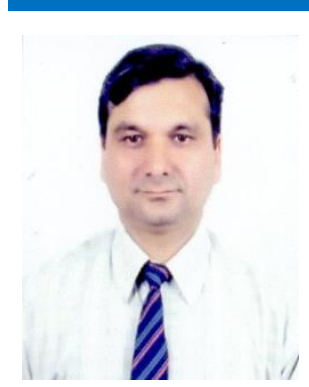

K. K. Bamzai, is Professor and Incharge of Crystal Growth and Material Research Laboratory, Department of Physics \& Electronics, University of Jammu, Jammu, India. Dr.Bamzai did his Masters Degree in Physics (1986), M.Phil in Physics (1991) and Ph.D (1997) from University of Jammu. The research areas of interest include crystal growth, ceramic preparation, characterization and study of various properties of complex oxides, rare earth containing materials etc. Till date he has published about 60 papers in international journals of repute, guided 8 students for their Ph.D. degree and 24 for their M.Phil degree and published one book.

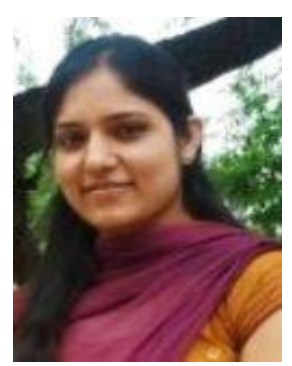

Rashmi Gupta, Senior Research Scholar in the Crystal Growth \& Material Research Laboratory, Department of Physics \& Electronics, University of Jammu, Jammu, India. Ms Gupta did her Bachelor's degree from Govt. Degree College Ramnagar, Jammu (2008), Masters Degree in Physics (2010) and M.Phil (2012) from the University of Jammu. At present, working for Ph.D degree on preparation and characterization of lead niobate based mixed composite.

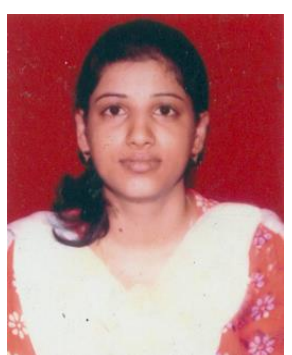

Engineering, Babliana, Jammu.

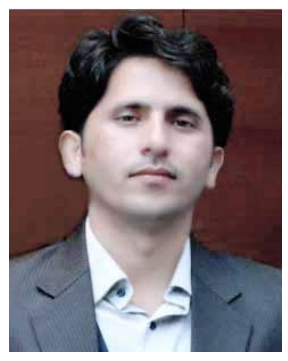
College of Engineering, Babliana, Jammu.
Vishal Singh, is Senior Post Doctoral Research Fellow, Crystal Growth \& Material Research Laboratory, Department of Physics \& Electronics, University of Jammu, Jammu, India. Dr. Vishal did his Bachelors degree from G. D. C Kathua, Jammu, (2000), Masters Degree in Physics from H.N.B Garhwal University, Srinagar, Uttrakhand, (2002) and M.Phil in Physics (2005) from Jammu University. He has to his credit till date about 12 international publications. At present, Dr.

Shivani Suri, Senior Post Doctoral Research Research Laboratory, Department of Physics \& Electronics, University of Jammu, Jammu, India. Dr. Shivani did her Bachelors degree Masters Degree in Physics (2005) and (2002), (2006) from the Jammu University. She has to her credit till date about 08 international publications. At present, Dr. Suri is working as Assistant Prof. in M B S College of 


\section{Introduction}

Phosphates are considered as the most interesting class of materials which have attracted more and more interest on synthesis, crystallography, electro-optical properties and so on $[1,2]$. Over the past few decades, the technology and science of materials has advanced rapidly for the synthesis and characterization of new non-linear optical materials. Potassium dihydrogen phosphates (KDP), an important class of material belonging to phosphate group have gained special interest due to their vide applications as ferroelectric, piezoelectric, pyroelectric as well as laser modulator [3, 4]. Studies on the preparation and characterization of calcium phosphate have been widely investigated [5-8]. Synthesis of some transition metal phosphates by different synthesis conditions and medium agents have been reported [9,10]. The precipitation of calcium phosphates in the presence of increasing cadmium amount was studied at $25^{\circ} \mathrm{C}$ in dilute ammonia solutions [11]. An amorphous precipitate, an apatite - calcium phosphate and the compound $\mathrm{Cd}_{5} \mathrm{H}_{2}\left(\mathrm{PO}_{4}\right)_{4} \cdot 4 \mathrm{H}_{2} \mathrm{O}$ are formed according to $\mathrm{pH}$ and cadmium concentration. The effect of cadmium substitution on various properties of pure calcium hydrogen phosphate has been studied by Bamzai et al [12]. Recently, effect of rare earth on thermo luminescence properties of $\mathrm{CaSO}_{4}$ phosphors have been investigated by Wani et al [13]

The alkaline earth phosphates have received enormous importance with respect to their use as phosphor matrices [14]. The effect of doping on gel grown crystals has been studied by many investigators [15-17]. Inorganic phosphates encompass a large class of diverse materials with a vide range of applications which includes catalysts, linear and non - linear optical components, solid electrolytes for batteries, in synthetic replacement for bone and teeth and many more $[18,19]$. Magnesium hydrogen phosphate also known as Newberyite $\left(\mathrm{MgHPO}_{4} \cdot 3 \mathrm{H}_{2} \mathrm{O}\right)$ has interesting application as far as their bioactivity is concerned [20]. Newberyite $\left(\mathrm{MgHPO}_{4} \cdot 3 \mathrm{H}_{2} \mathrm{O}\right)$, together with another phosphate mineral brushite $\left(\mathrm{CaHPO}_{4} \cdot 2 \mathrm{H}_{2} \mathrm{O}\right)$ have contributed to pre-enzymatic phosphorylation and thus to the development of life itself. Single crystals of anhydrous magnesium hydrogen phosphate $\left(\mathrm{MgHPO}_{4}\right)$ are of considerable interest, especially in fundamental studies of phase transitions and because of their important dielectric, ferroelectric, piezoelectric and optical properties. Kanchana et al [21] carried out the growth of strontium chromium magnesium hydrogen phosphate (SrCrMHP) crystals by silica gel method. They extended their research work and reported the growth of SrCaMHP crystals [22].

In the present investigations, the main objective of the work is to report growth, characterization, mechanical and dielectric behavior of pure and cadmium $(\mathrm{Cd})$ mixed magnesium hydrogen phosphate crystals. Growth of mixed crystals is interesting because their characteristics change from those of the crystals of single components grown separately, e.g., mixed crystals are found to be harder than pure ones $[23,24]$. Cadmium $\left(\mathrm{Cd}^{2+}\right)$ ion which is transition metal has been selected for the modified magnesium hydrogen phosphate because its ionic radius $(0.97 \AA \hat{)})$ is

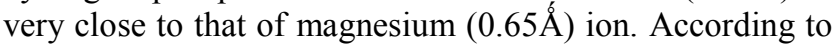

Goldsmith rule, the dopant cation enters into the sites if the radius of the substituted ion and the replaced ion does not differ by $15-20 \%$. Also, literature survey unfolds that no work has so far been reported on growth of mixed crystal of $\mathrm{Cd}$ modified magnesium hydrogen phosphate in gels at room temperature. The effect of substitution on various characteristics of the parent material has been investigated by carrying out systematic study on the crystal of the modified composition.

\section{Experimental}

\section{Materials}

To carry out the growth of magnesium hydrogen phosphate and cadmium magnesium hydrogen phosphate, the starting materials were the following: orthophosphoric acid $\left(\mathrm{H}_{3} \mathrm{PO}_{4}\right)$ from Loba Chemie (AR Grade $98 \%$ ); sodium metasilicate $\left(\mathrm{Na}_{2} \mathrm{SiO}_{3} .5 \mathrm{H}_{2} \mathrm{O}\right)$ from $\mathrm{s} d$ Fine-chem Limited (LR Grade $97 \%$ ); magnesium chloride $\left(\mathrm{MgCl}_{2} \cdot 6 \mathrm{H}_{2} \mathrm{O}\right)$ from $\mathrm{s}$ d Fine-chem Limited (AR Grade 98\%) and cadmiun chloride $\left(\mathrm{CdCl}_{2} \cdot \mathrm{H}_{2} \mathrm{O}\right)$ from $\mathrm{s}$ d Fine-chem Limited (AR Grade 99\%).

\section{Method}

The growth of magnesium hydrogen phosphate (hereafter referred as MHP) and cadmium mixed magnesium hydrogen phosphate (referred as CdMHP) has been carried out by using room temperature solution technique i.e., gel encapsulation technique. The method involves incorporating one reactant called the lower reactant into the gelling mixture and later diffusing another reactant called the upper reactant into the gel medium. This leads to a very high supersaturation condition initiating the nucleation necessary for the growth of crystals.

\section{Preparation of hydrosilica gel}

In order to grow crystals from silica gel, first of all silica gel solution of desired molarity was prepared by dissolving sodium metasilicate (SMS) powder in distilled water. The $\mathrm{pH}$ of the SMS solution must be lowered in order to have proper gelation. This can be achieved by mixing an acid with the solution. Since in the present case phosphate crystals are to be grown, therefore, orthophosphoric acid of desired molarity was added gently to the prepared SMS solution with constant stirring to adjust the $\mathrm{pH}$ of the solution and also as the source of anions for crystallization of the compound. The dissociation of orthophosphoric acid system can be represented by three dissociation equilibrium and the presence of various ions at various $\mathrm{pH}$ values [25]. Based on these results, the gel $\mathrm{pH}$ in the range 5-7 has been used in which the $\mathrm{HPO}_{4}{ }^{2-}$ ions dominate or exist alone. The acidified gel was then poured into the test tube. This gel was allowed to set in the crystallizer and then aged for desired time. In our experiments, we used gels of ages 72 , 96, 120, 144 and $198 \mathrm{~h}$.

\section{Synthesis of pure MHP}

After the gel was set and aged, the supernatant (magnesium chloride) solution of desired molarity was poured along the 
sides of the tube, ensuring that this process does not break the gel. As soon as upper reactant comes in contact with the lower reactant, precipitation starts immediately suggesting spontaneous nucleation. All the experiments were conducted in the room temperature range $30-40^{\circ} \mathrm{C}$. The expected chemical reaction in case of magnesium hydrogen phosphate (where lower reactant is orthophosphoric acid and upper reactant is magnesium chloride) is:

$\mathrm{Mg}^{2+}+\mathrm{HPO}_{4}^{2-} \longrightarrow \mathrm{MgHPO}_{4}+$ by-products

\section{Synthesis of CdMHP}

For the growth of $10 \%$ cadmium mixed magnesium hydrogen phosphate crystals, lower reactant remains the same. However, for upper reactant a mixture of $\mathrm{CdCl}_{2}$ and $\mathrm{MgCl}_{2}$ in proper ratio was used. The diffusion of $\mathrm{Cd}^{2+}$ and $\mathrm{Mg}^{2+}$ ions through narrow pores of silica gel leads to the reaction between these ions and $\mathrm{HPO}_{4}{ }^{2-}$ ions of lower reactant already present in the gel suggesting spontaneous nucleation and the expected chemical reaction is:

$\mathrm{Cd}^{2+}+\mathrm{Mg}^{2+}+\mathrm{HPO}_{4}{ }^{2-} \longrightarrow \mathrm{CdMgHPO}_{4}+$ by-products

In order to obtain the optimum conditions conducive for the growth of MHP and CdMHP, number of experiments were carried out by varying the various growth parameters including upper reactant concentration, lower reactant concentration, gel concentration, gel $\mathrm{pH}$ and gel ageing. The optimum condition for the growth of good quality single crystal is given in Table $\mathbf{1}$.

Table 1. Optimum conditions for the growth of magnesium hydrogen phosphate (MHP) and cadmium magnesium hydrogen phosphate (CdMHP) crystals.

\begin{tabular}{ccc}
\hline Varying parameter & MHP & CdMHP \\
\hline $\begin{array}{c}\text { Lower reactant } \\
\text { concentration }\end{array}$ & $0.5 \mathrm{M}$ & $0.5 \mathrm{M}$ \\
Upper reactant & $0.5 \mathrm{M}$ & $1 \mathrm{M}$ \\
concentration & & \\
Gel pH & 7 & 6 \\
Gel ageing & $96 \mathrm{~h}$ & $198 \mathrm{~h}$ \\
Gel concentration & $0.5 \mathrm{M}$ & $0.5 \mathrm{M}$ \\
Temperature & $30-40^{\circ} \mathrm{C}$ & $30-40^{\circ} \mathrm{C}$ \\
\hline
\end{tabular}

\section{Characterization}

The incident light microscope "EPIGNOST" was used for the rapid examination of the grown crystals. Single crystal X'Calibur Oxford X-ray diffractometer was used to find out the crystal system, whereas the powder pattern was also obtained using powder X-ray diffractometer (Rigaku Co. Ltd. Japan) with $\mathrm{Cu} \mathrm{K \alpha}$ radiation $(\lambda=1.5406 \AA)$ with a scanning rate of $2 \% \mathrm{~min}$. Hardness studies have been carried out by using auto detection microhardness analyzer (HMV2 of Shimadzu, Japan). The dielectric measurements were recorded with the help of automated impedance analyzer (4192A LF model) interfaced with USB - GPIB converter 82357 (Agilent) and further automated by using a computer for data recording, storage and analysis.

\section{Results and discussion}

\section{Structural characterization}

Some of the good quality single crystals of MHP and CdMHP placed on a microslide is shown in Fig. 1 (a \& b) respectively.

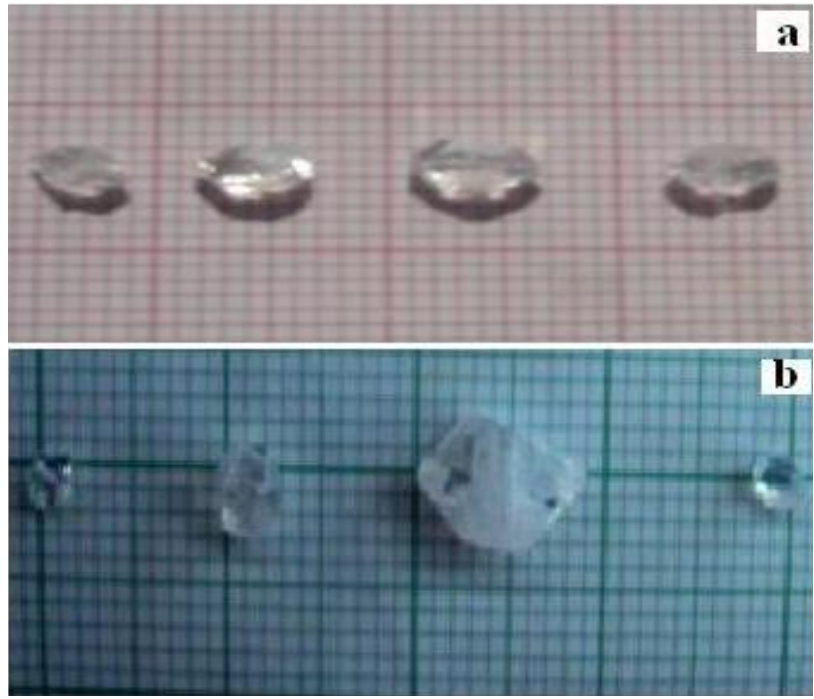

Fig. 1. Some of the good quality single crystals of (a) magnesium hydrogen phosphate (MHP) and (b) cadmium magnesium hydrogen phosphate (CdMHP) placed on a microslide.

For the micromorphological studies, the crystals were placed under the incident light microscope "EPIGNOST". The optical micrographs of MHP and CdMHP is shown in Fig. 2 (a \& b) respectively. Fig. 2 (a) shows the formation of a given plane on the surface of pure MHP crystal, whereas Fig. 2 (b) represents the optical micrograph of CdMHP crystal showing clearly the hexagonal morphology along with a clear plane.

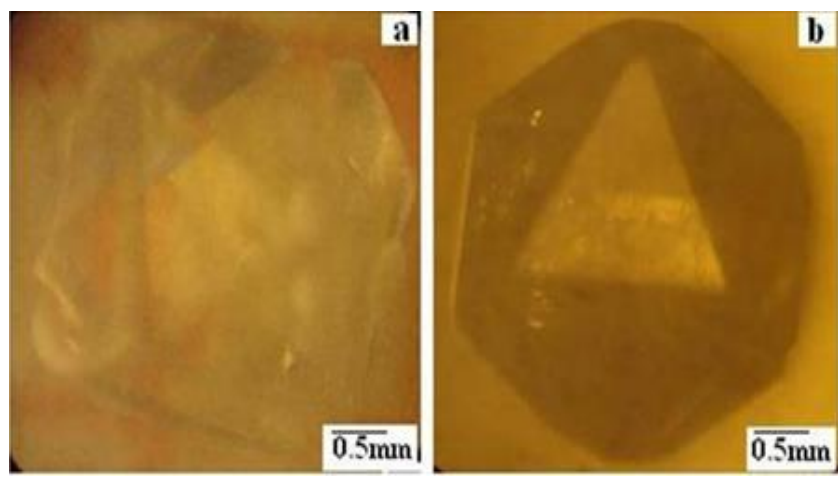

Fig. 2. Optical micrograph showing (a) formation of a given plane on the surface of magnesium hydrogen phosphate crystal and (b) hexagonal morphology on the surface of cadmium magnesium hydrogen phosphate crystal.

The powder $\mathrm{X}$ - ray diffraction pattern for MHP and CdMHP is shown in Fig. 3 (a \& b) respectively. The occurrence of highly resolved intense peaks at specific $2 \theta$ Bragg angles indicates the crystallinity of the grown material. 


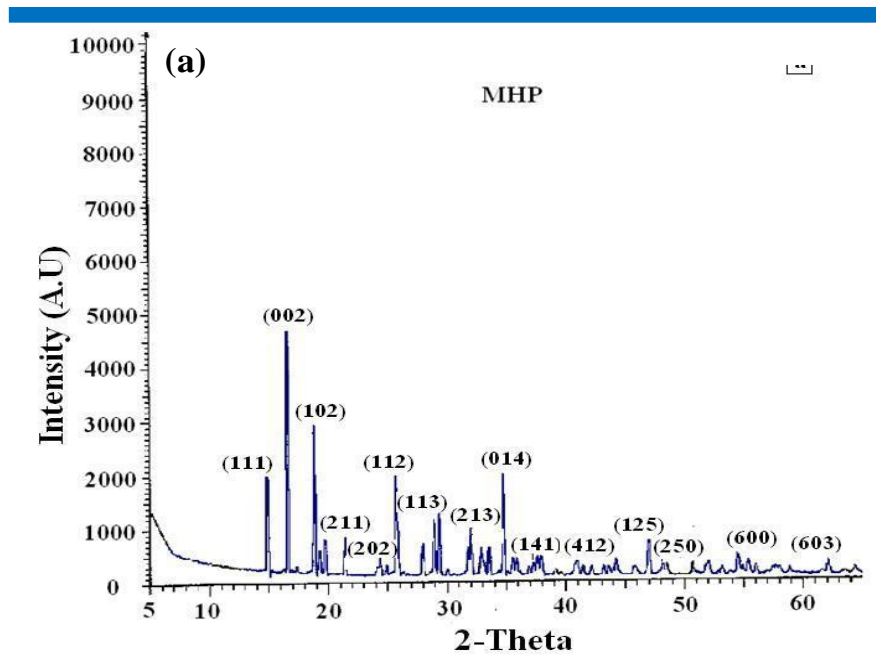

change in the internal structure of crystals due to change in bond lengths as a result of doping. Thus, it has been observed that doping shifts peak value towards higher angle, indicating an increase in the value of lattice constants. Single crystal X - ray analysis establishes that MHP and CdMHP belong to orthorhombic crystal system. The lattice parameters obtained for both the systems is given in Table 3. From the powder as well as single crystal $\mathrm{X}$ - ray diffraction results, it can be concluded that MHP and CdMHP have the orthorhombic crystal system with space group Pbca. Thus, it is clear that doping of about $10 \% \mathrm{Cd}$ into MHP does not change the crystal system.

Table 3. Lattice parameters for magnesium hydrogen phosphate (MHP) and cadmium magnesium hydrogen phosphate (CdMHP) crystals.

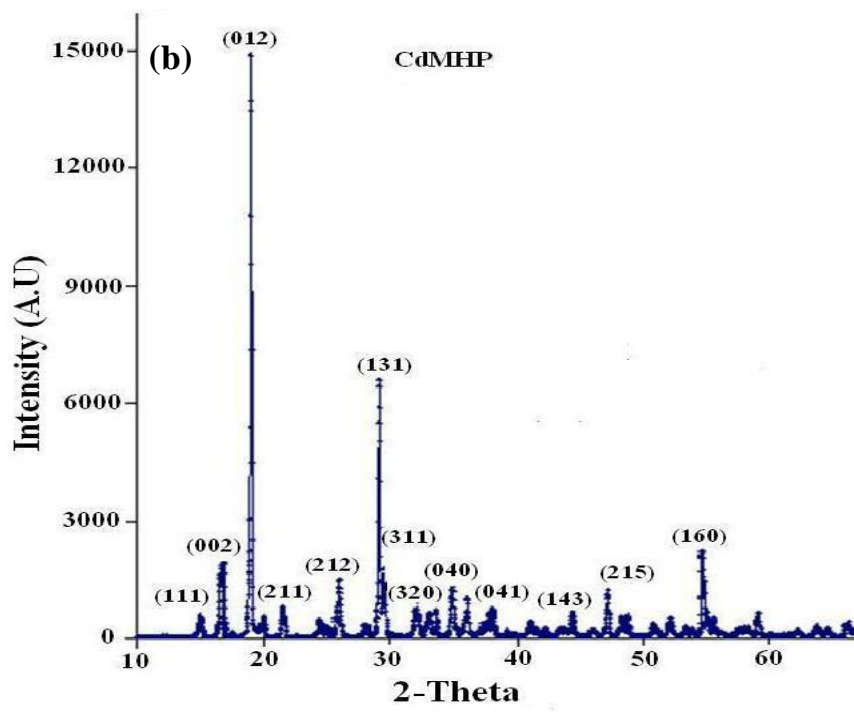

\begin{tabular}{ccc}
\hline Lattice parameter & MHP & CdMHP \\
$\mathrm{a}$ & $9.9445(18) \AA$ & $10.0147(2) \AA$ \\
$\mathrm{b}$ & $10.2080(2) \AA$ & $10.2179(2) \AA$ \\
$\mathrm{c}$ & $10.6636(10) \AA$ & $10.6819(2) \AA$ \\
$\alpha$ & $90.024(13)^{\circ}$ & $90^{\circ}$ \\
$\beta$ & $89.824(12)^{\circ}$ & $90^{\circ}$ \\
$\gamma$ & $89.905(15)^{\circ}$ & $90^{\circ}$ \\
Volume, $\mathrm{V}$ & $1082.45(10)(\AA)^{3}$ & $1093.07(03)(\AA)^{3}$ \\
Space group & Pbca & $\mathrm{Pbca}$ \\
\hline
\end{tabular}

\section{Mechanical characterization}

The mechanical strength of the grown crystals was done by microhardness measurement technique. For carrying out the hardness studies on MHP and CdMHP, smooth and clean face of the crystal was selected and subjected to indentation test at room temperature. Loads ranging from $0.2452 \mathrm{~N}$ to $1.961 \mathrm{~N}$ were used for indentation keeping the indenter at right angles to the surface of the crystal for 10 sec in all cases. The distance between any two consecutive indentations was suitably adjusted in order to ensure that the effects were independent of each other. The Vicker's microhardness value $\left(\mathrm{H}_{\mathrm{v}}\right)$ was calculated using the formula:

Fig. 3. (a) Powder X-ray diffraction pattern of magnesium hydrogen phosphate (MHP) and (b) Powder X-ray diffraction pattern of cadmium magnesium hydrogen phosphate (CdMHP).

The details of the $\mathrm{X}$ - ray diffraction plot depicting $\mathrm{d}$ spacing and corresponding [hkl] planes for MHP and CdMHP crystal is given in Table 2.

Table 2. Compiled data of various hkl planes corresponding to different Bragg angle and interplaner spacing for magnesium hydrogen phosphate (MHP) and cadmium magnesium hydrogen phosphate (CdMHP).

\begin{tabular}{|c|c|c|c|c|c|c|c|}
\hline \multicolumn{2}{|c|}{ d-Spacing/§̊ } & \multicolumn{2}{|c|}{$2 \theta / \theta$} & \multicolumn{2}{|c|}{ [hkl]Planes } & \multicolumn{2}{|c|}{ Intensity/counts } \\
\hline$\underline{\mathrm{MHP}}$ & $\underline{\text { CdMHP }}$ & $\underline{\mathrm{MHP}}$ & $\underline{\mathrm{CdMHP}}$ & $\underline{\mathrm{MHP}}$ & $\underline{\text { CdMHP }}$ & $\underline{\mathrm{MHP}}$ & $\underline{\mathrm{CdMHP}}$ \\
\hline 5.9496 & 5.8939 & 14.878 & 15.019 & 111 & 111 & 46.30 & 3.6 \\
\hline 5.3474 & 5.2677 & 16.564 & 18.817 & 002 & 002 & 100 & 12.6 \\
\hline 4.1482 & 4.1218 & 21.403 & 21.542 & 211 & 211 & 17.2 & 5.2 \\
\hline 3.6558 & 3.4298 & 24.327 & 25.958 & 202 & 212 & 10.2 & 9.8 \\
\hline 2.7926 & 2.7997 & 32.023 & 31.940 & 213 & 320 & 21.4 & 5.6 \\
\hline 2.5808 & 2.5687 & 34.732 & 34.901 & 014 & 040 & 41.5 & 9.6 \\
\hline 1.9301 & 1.9248 & 47.042 & 47.181 & 125 & 215 & 15.1 & 8.0 \\
\hline 1.6566 & 1.6795 & 55.417 & 54.600 & 600 & 160 & 7.2 & 14.1 \\
\hline
\end{tabular}

From the diffraction pattern, it can be clearly seen that the substitution of $\mathrm{Cd}$ in place of $\mathrm{Mg}$ ions in pure MHP crystals lead to shift in the positions of peaks indicating a

$\mathrm{H}_{\mathrm{v}}=\left(2 \operatorname{Sin} 68^{\circ}\right) \mathrm{P} / \mathrm{d}^{2} \quad$ or $\quad \mathrm{H}_{\mathrm{v}}=1.8544 \mathrm{P} / \mathrm{d}^{2}$

where ' $\mathrm{P}$ ' is the applied load in Newton and ' $\mathrm{d}$ ' is the diagonal length of the indentation mark in micrometer. The error in $\mathrm{H}_{\mathrm{v}}$ was estimated through the relation:

$$
\Delta \mathrm{H}_{\mathrm{v}}=1.8544\left[(\Delta \mathrm{P} / \mathrm{Y})^{2}+\left(\mathrm{P} \Delta \mathrm{Y} / \mathrm{Y}^{2}\right)^{2}\right]^{1 / 2}
$$

where $\mathrm{Y}=\mathrm{d}^{2}, \Delta \mathrm{Y}=2 \mathrm{~d} \Delta \mathrm{d}, \Delta \mathrm{P}, \Delta \mathrm{Y}$ and $\Delta \mathrm{d}$ being error in $\mathrm{P}, \mathrm{Y}$, and $\mathrm{d}$ respectively. The study on variation of microhardness with applied load for MHP crystals has already been carried out and reported [26]. It was found that microhardness value first increases and then becomes independent of load. However, there is no report regarding the microhardness behaviour with applied load for CdMHP crystals. A survey of literature suggests that different materials behave differently so far their dependence of microhardness on applied load is concerned. It is reported that microhardness is: i) independent of load [27]; ii) increase or decrease with load [28, 29]; and iii) shows complex variation with change in load [30]. 
Therefore, it is interesting to see how $\mathrm{Cd}$ doping in MHP system responds to the indentation. Fig. 4 shows the indentation impression at a load of $0.49 \mathrm{~N}$. Table 4 gives the compiled data on the microhardness studies of CdMHP crystal. The behaviour of Vicker's hardness number with applied load is somewhat complex.

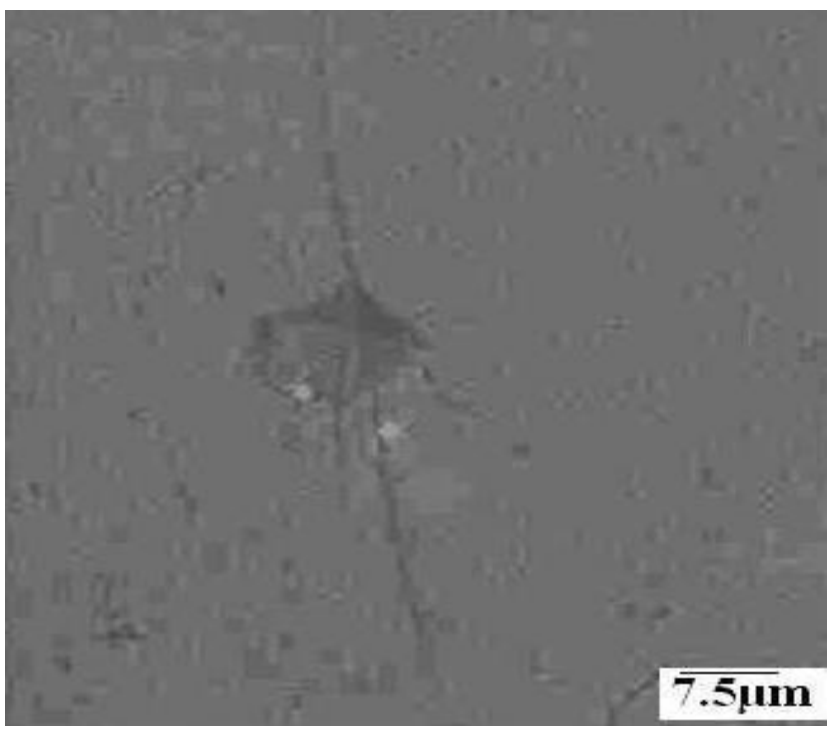

Fig. 4. Shows indentation impression at a load of $0.49 \mathrm{~N}$ for cadmium magnesium hydrogen phosphate.

Table 4. Results of microhardness studies on cadmium magnesium hydrogen phosphate (CdMHP) crystal.

\begin{tabular}{ccccc}
\hline S. No. & $\begin{array}{c}\text { Load }(\mathbf{P}) \\
(\mathbf{N})\end{array}$ & $\begin{array}{c}\text { Average length } \\
(\mathbf{d}) \\
(\mathbf{i n ~} \mathbf{~})\end{array}$ & $\begin{array}{c}\text { Hardness }\left(\mathbf{H}_{\mathrm{v}}\right) \\
\mathbf{H}_{\mathbf{v}}=\mathbf{1 . 8 5 4 4} / \mathbf{d}^{2} \\
\left(\mathbf{M N} / \mathbf{m}^{2}\right)\end{array}$ & $\begin{array}{c}\Delta \mathbf{H}_{\mathrm{v}}=\mathbf{1 . 8 5 4 4} \\
(\mathbf{\Delta} \mathbf{P} / \mathbf{Y})^{2}+ \\
\left.\left(\mathbf{P} \Delta \mathbf{Y} / \mathbf{Y}^{2}\right)^{2}\right]^{1 / 2}\end{array}$ \\
\hline 1. & 0.245 & $10.26 \times 10^{-6}$ & 4319 & 401 \\
2. & 0.490 & $12.38 \times 10^{-6}$ & 5928 & 335 \\
3. & 0.980 & $16.55 \times 10^{-6}$ & 6634 & 235 \\
4. & 1.961 & $16.55 \times 10^{-6}$ & 13276 & 418 \\
5. & 2.942 & $16.45 \times 10^{-6}$ & 20161 & 626 \\
6. & 4.903 & $16.84 \times 10^{-6}$ & 32061 & 959 \\
7. & 9.807 & $18.58 \times 10^{-6}$ & 52680 & 1420 \\
\hline
\end{tabular}

It shows increasing trend with increase in applied load, where at first, the increase for smaller loads is less as compared to the higher load. The value of Vicker's hardness ranges from $4319-52680 \mathrm{MN} / \mathrm{m}^{2}$ in the load ranging from $0.245-9.807 \mathrm{~N}$, respectively. The explanation for the variation of $\mathrm{H}_{\mathrm{v}}$ with load in complex fashion can be given on the basis of role played by the surface layer in deciding its hardness property. The diamond pyramid indenter used in the present investigation for calculating microhardness values penetrate considerably deeper than the thickness of the surface layer. However, as the depth of penetration increases with increasing load, the effect of the surface layer of the crystal becomes less marked, thereby, indicating the increase in the hardness value. For much larger loads, when the indenter reaches a depth at which undistorted layers of the material exists and the elastic properties of the inner material predominate over the surface properties, the microhardness is expected to cease its dependence on load which in the present case, for CdMHP has not been obtained. Berzina et al [31] reported for various alkali halide crystals, the anomalous behaviour of microhardness at low loads is greatest in crystals with large surface energy and thus related the microhardness particularly, in low load region on the surface energy of the solids. Thus, we can say that in the present case also, the surface energy plays an important role for the increase in the values of microhardness.

\section{Electrical characterization}

The electric characterization includes the response of dielectric constant to an applied electric field. The variation of dielectric constant $\left(\varepsilon^{\prime}\right)$ can be attributed to different types of polarization which comes into play at different stages of its response to varying temperature and frequency of the applied alternating field. A study of variation of dielectric constant with temperature and frequency of the applied electric field is very useful in the study of phase transitions taking place in materials. For MHP and CdMHP, the dependence of dielectric constant on temperature was studied in the temperature range of $30-400^{\circ} \mathrm{C}$ and in the frequency range of $1-1000 \mathrm{kHz}$ of the applied a.c field.
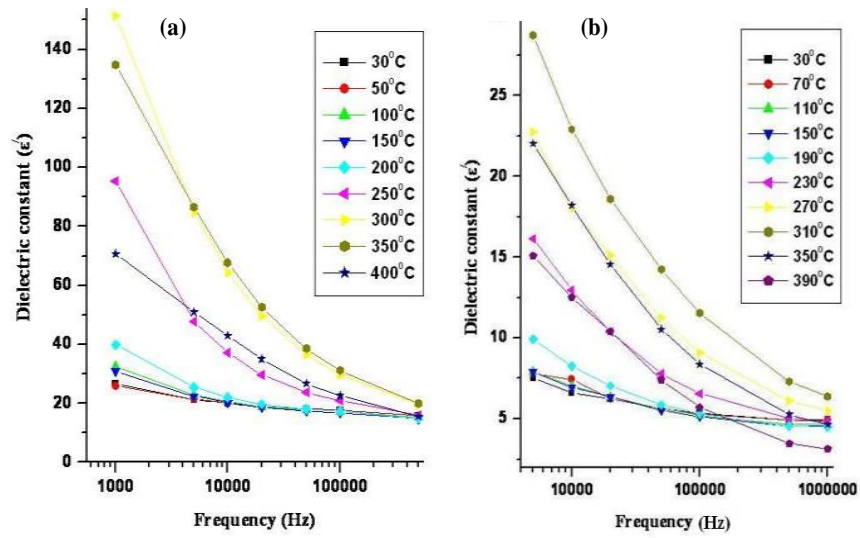

Fig. 5. (a) Plot showing variation of dielectric constant with temperature in case of magnesium hydrogen phosphate (MHP) and (b) variation of dielectric constant with temperature in case of cadmium magnesium hydrogen phosphate (CdMHP).

\section{Variation of dielectric constant with frequency at different temperature}

The dependence of dielectric constant on frequency of the applied a.c field in case of MHP and CdMHP is shown in Fig. 5 (a \& b) respectively. It can be seen from the figure that the dielectric constant decreases continuously with increasing frequency and attains almost saturation at higher frequencies. The decrease in the value of dielectric constant with increasing frequency is a normal dielectric behaviour and has been reported earlier [32-35]. At each particular temperature, the dielectric constant has a maximum value at lower frequency. This type of behaviour indicates higher space charge polarizibility in the low frequency region. As the frequency increases, the dipole do not comply with the varying external field resulting in the decrease in polarization which, in turn results in the decrease in the value of dielectric constant with increasing frequency [36]. 

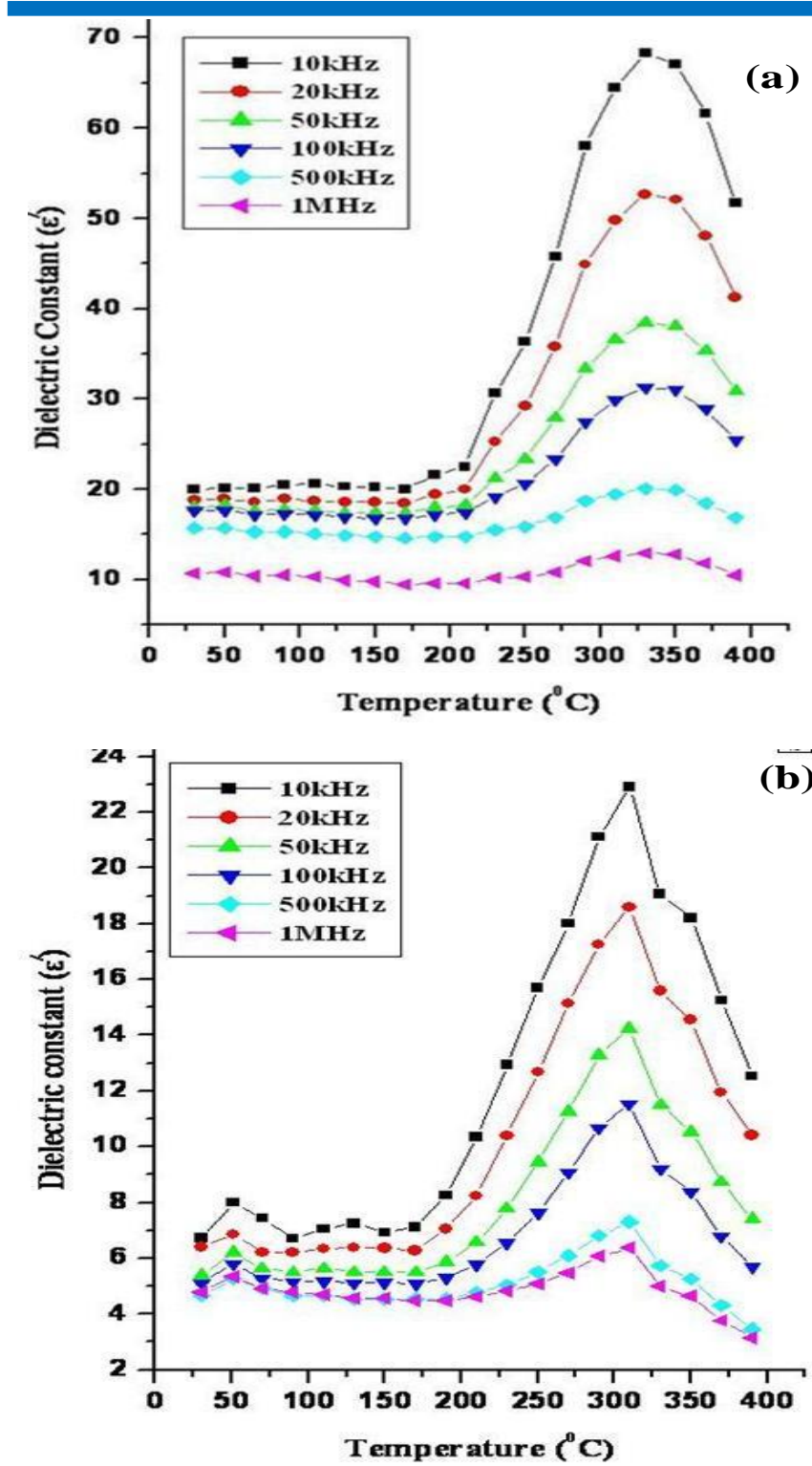

Fig. 6. (a) Plot showing variation of dielectric constant with temperature in case of magnesium hydrogen phosphate (MHP) and (b) variation of dielectric constant with temperature in case of cadmium magnesium hydrogen phosphate CdMHP.

Table 5. Data regarding dielectric constant and their corresponding transition temperature in case of magnesium hydrogen phosphate (MHP) and cadmium magnesium hydrogen phosphate (CdMHP) crystals.

\begin{tabular}{ccccc}
\hline Frequency & \multicolumn{2}{c}{ MHP } & \multicolumn{2}{c}{ CdMHP } \\
& $\boldsymbol{\varepsilon}^{\prime}$ & $\mathbf{T}_{\mathbf{C}}$ & $\boldsymbol{\varepsilon}^{\prime}$ & $\mathbf{T}_{\mathbf{C}}$ \\
\hline $10 \mathrm{kHz}$ & 68.3 & $330^{\circ} \mathrm{C}$ & 22.91 & $310^{\circ} \mathrm{C}$ \\
$100 \mathrm{kHz}$ & 31.3 & $330^{\circ} \mathrm{C}$ & 11.54 & $310^{\circ} \mathrm{C}$ \\
$1 \mathrm{MHz}$ & 12.9 & $330^{\circ} \mathrm{C}$ & 6.37 & $310^{\circ} \mathrm{C}$ \\
\hline
\end{tabular}

Variation of dielectric constant with temperature at different frequencies

Fig. 6 (a \& b) shows the behaviour of dielectric constant $\left(\varepsilon^{\prime}\right)$ with temperature in case of MHP and CdMHP respectively. From the graph, it is clear that MHP has a high dielectric constant as compared to CdMHP. In case of MHP, the dielectric constant $\left(\varepsilon^{\prime}\right)$ under the application of frequency varies little upto the temperature of $200^{\circ} \mathrm{C}$. As the temperature increases, the value of dielectric constant increases and reaches a maximum value of 68 for a frequency of $10 \mathrm{kHz}$ at a temperature of $330^{\circ} \mathrm{C}$. The value of $\varepsilon$ decreases after $330^{\circ} \mathrm{C}$ and reaches upto a value of 52 at $390^{\circ} \mathrm{C}$. For other frequencies i.e., from $20 \mathrm{kHz}-1 \mathrm{MHz}$, the peak value of dielectric constant is also observed at a temperature of $330^{\circ} \mathrm{C}$. Thus, the peak value of $330^{\circ} \mathrm{C}$ is observed for all the frequencies considered, thereby, suggesting that the transition temperature in case of MHP is $330^{\circ} \mathrm{C}$. In case of CdMHP, the variation of dielectric constant with frequency of applied ac field is very little upto the temperature of $190^{\circ} \mathrm{C}$. As the temperature increases, the value of dielectric constant increases and reaches a maximum value of 23 for a frequency of $10 \mathrm{kHz}$ at a temperature of $310^{\circ} \mathrm{C}$. Beyond $310^{\circ} \mathrm{C}$, the value of $\varepsilon^{\prime}$ decreases and reaches upto a value of 13 at $390^{\circ} \mathrm{C}$. For other frequencies i.e., from $20 \mathrm{kHz}-1 \mathrm{MHz}$, the peak value of dielectric constant is also observed at a temperature of $310^{\circ} \mathrm{C}$. Thus, the peak value of $310^{\circ} \mathrm{C}$ is observed for all the frequencies considered, thereby suggesting that the transition temperature in case of CdMHP is $310^{\circ} \mathrm{C}$. Table 5 gives the data regarding dielectric constant and their corresponding transition temperature in case MHP and CdMHP. From the above observation, it is clear that the transition metal $(\mathrm{Cd})$ doping in MHP system decreases the transition temperature and also its dielectric constant.

\section{Conclusion}

Growth of magnesium hydrogen phosphate (MHP) and cadmium mixed magnesium hydrogen phosphate (CdMHP) was accomplished by employing room temperature solution technique i.e., gel encapsulation technique. Optimum conditions for successful growth of good quality single crystals have been worked out. The crystals of MHP and CdMHP belong to orthorhombic crystal system with space group Pbca. A slight change in the lattice parameters takes place on incorporation of $\mathrm{Cd}$ into the lattice of MHP system. Doping of cadmium does not change the crystal structure of MHP. Cadmium doping plays an important role in the mechanical properties of MHP crystals. The behavior of Vicker's hardness number with applied load is somewhat complex where the increase for smaller load is less as compared to the higher loads. The value of Vicker's hardness number ranges from $4319-52680 \mathrm{MN} / \mathrm{m}^{2}$ in the load range of $0.245-9.807 \mathrm{~N}$ respectively. The dielectric constant decreases continuously with increasing frequency and attains almost saturation at higher frequencies for MHP and CdMHP crystals. The decrease in the value of dielectric constant with increasing frequency is a normal dielectric behavior. The transition metal doping of cadmium in MHP decrease remarkably the value of dielectric constant from 68 to 23 at a frequency of $10 \mathrm{kHz}$. Also the doping of cadmium affects the transition temperature of MHP system. The transition temperature 
values decrease from $330^{\circ} \mathrm{C}$ in case of MHP to $310^{\circ} \mathrm{C}$ in case of CdMHP.

\section{Reference}

1. Dinamani, M; Kamath, P. V. Mat. Res. Bull. 2001, 36, 2043. DOI: $10.1016 / \mathrm{S} 0025-5408(01) 00682-1$

2. Sales, B. C.; Chaoumakos, B. C. J. Non - Cryst. Sol. 1993,159, 121. DOI: $10.1016 / 0022-3093(93) 91289-\mathrm{F}$

3. Mullin, J. W.; Amatavivadhana, A. J. Appl.Chem. 1967, 17, 151. DOI: $10.1002 /$ jetb. 5010170508

4. Joshi, M. S.; Paul, B. K. J. Cryst. Growth. 1974, 22, 323. DOI: $\underline{10.1016 / 0022-0248(74) 90078-5}$

5. Kumar, R.; Prakash, K. H.; Cheang, P.; Khor, K. A. Langmuir 2004, 20, 5196. DOI: $10.1021 / \mathrm{la} 049304 \mathrm{f}$

6. Bose, S.; Saha, S. K. J. Chem. Mater. 2003, 15, 4464. DOI: $10.1021 / \mathrm{cm} 0303437$

7. Sadasivan, S.; Khushalani, D.; Mann, S. Chem. Mater. 2005, 17, 2765. DOI: $10.1021 / \mathrm{cm} 047926 \mathrm{~g}$

8. Wojciech, L. S.; Pavel, S.; Byrappa, K.; Richard, E. R.; Kevor, S. T.; Victor, F. J. Biomaterials 2002, 23, 699.

9. Scaccia, S.; Carewska, M.; Bartolomeo, A. D.; Prosini, P. P. Thermochim. Acta 2003,397, 135. DOI: $10.1016 / \mathrm{S} 0040-6031(02) 00292-7$

10. Manthiram, A.; Kim, J. Chem. Mater. 1998, 10, 2895. DOI: $10.1021 / \mathrm{cm} 980241 \mathrm{u}$

11. Lundager Madsen, H. E; Abbona, F.; Barrase E. Crys. Res. Tec. 2004, $39,235$.

DOI: $\underline{10.1002 / \mathrm{crat} .200310176}$

12. Bamzai, K. K.; Suri, S.; Singh, V. Mater. Chem. \& Phys. 2012, 135, 158.

DOI: $10.1016 /$ j.matchemphys.2012.04.040

13. Wani, J. A.; Atone, M. S.; Dhoble, S. J. Adv. Mat. Lett. 2013, 4, 363. DOI: $10.1088 / 0022-3727 / 24 / 3 / 020$

14. Koelmans, H.; Cox, A. P. M. J. Electro Chem. Soc. 1957, 104, 442. DOI: $10.1149 / 1.2428621$

15. Dishovsky, N.; Boncheva-Mladenova, Z. J. Crys. Growth 1981, 51, 147. DOI: $10.1016 / 0022-0248(81) 90020-8$

16. Dennis, J.; Henisch, H. K. J. Electro Chem. Soc. 1967, 114, 263. DOI: $10.1149 / 1.2426564$

17. Gits, S.; Robert, M. C.; Lefaucheux, L. J. Crys. Growth 1985, 71, 203.

DOI: $10.1016 / 0022-0248(85) 90063-6$

18. Van Wazer, G. R. Phosphorus and its compounds, in: Chemistry, Interscience, New York, 1958, 1.

19. Kanazawa, T. Inorganic Phosphate Materials, Elsevier, New York, 1989.

20. Sutor, D. J.; Nature 1968, 218, 295.

DOI: $\underline{10.1038 / 2189295 \mathrm{aO}}$

21. Kanchana, G.; Suresh, P.; Sundaramoorthi, P.; Kolainathan, S.; Jeyanthi, G. P. J. Min. and Mat. Charact. and Eng. 2008, 7, 215.

22. Kanchana, G.; Sundaramoorthi, P.; Jeyanthi, G. P. J. Min. and Mat. Charact. and Eng. 2009, 81, 37.

23. Dharma Prakash, S. M.; Rao, M. Cryst. Res. Technol. 1987, 22, 1095. DOI: $10.1002 /$ crat. 2170220816

24. Kotru, P. N.; Razdan, A. K.; Wanklyn, B. M. J. Mater. Sci. 1989, 24, 2401. DOI: $10.1007 / \mathrm{BF} 01174502$

25. Pecsok, R. L.; Shields, L. D.; Cairns, T.; Mc Willian L. C. Modern Methods of Chemical Analysis (1976). John Wiley, New York.

26. Desai, C. C.; Patel, K. N. Cryst. Res. and Technol. 1989, 24, 681. DOI: $10.1002 /$ crat. 2170240709

27. Ascheron, C.; Huse, C.; Kuhn, G.; Neumann H., Cryst. Res. Technol. 1989, K 33, 24. DOI: $10.1002 /$ crat. 2170240226

28. Kotru, P. N.; Razdan, A. K.; Waanklyn, B. N. J. Mater. Sci. 1989, 24 , 793.

DOI: $10.1007 / \mathrm{BF} 01148759$

29. Balakrishan, K.; Vengatesan, B.; Kanniah, N.; Ramaswamy, P. J. Mater. Sci. Lett. 1990, 9, 7866. DOI: $10.1007 / \mathrm{BF} 00720158$

30. Bhatt, V. P.; Patel, R. M.; Desai, C. F. Cryst. Res. Technol. 1983, 18, 9 .

DOI: $10.1002 /$ crat.2170180919
31. Berzina, J. G.; Berman, J. B.; Savintsev, P. A. Sov. Phy. Cryst. 1965 9,483 .

32. Matthew, J. A.; Micheal G. B.; Drew; Susan Morris; David, A. R. Polyhedron. 1996, 15, 3377.

DOI: $10.1016 / 0277-5387(96) 00044-7$

33. Pike, G. E. Phys. Rev. 1972, B 6, 1572.

DOI: $10.1103 /$ PhysRevB.6.1572

34. Amin, B.; Kothari, A. J. Phys. Chem. Solids, 2004, 65, 965. DOI: $10.1016 / \mathrm{j} . j p c s .2003 .10 .058$

35. Politova, E. D.; Ivanova, V. V.; Kaleva, G. M. A.; Mosunov, V.; Segalla, A. G.; Yustefanovich, S.; Shvastsman, V. V.; Kholkin, A. L. Ferroelectrics 2004, 313, 129. DOI: $10.1080 / 00150190490903847$

36. Reicha, F. M.; El-Hi, M.; El-Sonabati, A. Z.; Diab, M. A. J. Phys. 1991, D 24, 369.

DOI: $10.1088 / 0022-3727 / 24 / 3 / 020$

\section{Advanced Materials Letters}

Publish your article in this journal

ADVANCED MATERIALS Letters is an international journal published quarterly. The journal is intended to provide top-quality peer-reviewed research papers in the fascinating field of materials science particularly in the area of structure, synthesis and processing, characterization, advanced-state properties, and applications of materials. All articles are indexed on various databases including $D O A J$ and are available for download for free. has fast and fair review articles, research articles, notes, letter to editor and short communications.

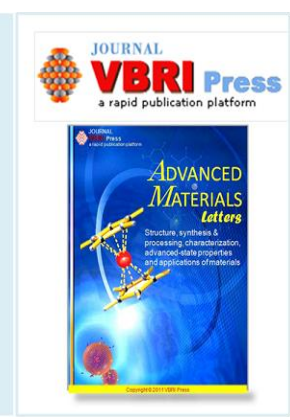

